\title{
The Social Gradient in Health: How Fair Retirement could make a Difference
}

\author{
Gry Wester, Department of Philosophy, University College London \\ Jonathan Wolff*, Department of Philosophy, University College London
}

*Corresponding author: Jonathan Wolff, Department of Philosophy, University College London. Email: j.wolff@ucl.ac.uk

Social inequalities in health in the UK persist despite attempts to reduce them. We argue that work and pensions constitutes an area of intervention where there is potential to make change happen. We propose that workers who are exposed to significant health risks through their occupation should be allowed to draw their state pension earlier, based on a minimum number of years in the workforce. We model this proposal on similar policies in other European countries. In our modification, the pension age and the retirement age would be separated, such that workers can receive a state pension whether or not they choose to continue working. This arrangement may encourage workers either to reduce their working hours or to change to less demanding or harmful work. The health of these workers would thereby benefit from reduced exposure to a harmful work environment, reduced stress and more opportunities for rest and relaxation. However, it has also been suggested that retirement is bad for mental health. In response, our proposal enables workers to phase in full retirement over a period of part-time work, and we believe that this would counter any potential negative effects on health caused by retirement.

\section{Introduction}

Reducing the social inequalities in health is considered to be an important goal, both by a broad spectrum of political parties as well as a range of theories of justice. In spite of a strong political will to achieve this goal, the Department of Health's recent status report (DH, 2008) shows that health inequalities have in fact grown in the last decade. The Labour government's stated target, as of 2003 , of reducing health inequalities by $10 \%$ by 2010 has not been met. Inequality in health remains a concern for the current coalition government $(\mathrm{DH}, 2010)$ (and indeed for many political parties across the spectrum), but in spite of scientific advances in identifying and describing the causal mechanisms by which health inequalities come about, it has proven very difficult to find solutions to the problem. Although it may be the case, as Professor Sir Michael Marmot has suggested, that it is too early still to see any effect of government interventions, it is very disappointing that health inequalities have increased. It is a major challenge to design public policy that is effective in reducing the health gradient.

The social gradient in health has been a well-known phenomenon at least since the publication of the Black Report in 1982. Since then, much light has been shed on the factors that cause this gradient. Roughly, the social determinants of health can be separated into material factors, including housing, nutrition, clothing and work conditions, and psychosocial factors such as social support and integration, the psychosocial work environment and control/autonomy (Marmot, 2004). Not all of the social determinants of health lend themselves to direct intervention by the government. However, the social determinants of health include some factors that are more directly under the government's control; for example, work, pensions and benefits. In these areas, the government can make changes that can be implemented and take effect relatively quickly. If we can design interventions that work through these channels, we might find that our efforts will be better rewarded.

One area where sensitive interventions could help reduce health inequalities concerns retirement practice and pensions. Currently, entitlement to the state pension in the UK is based on age; currently, 65 years for men and 60 for women, but expected to rise to 68 by 2046. We propose that some workers, in occupations that involve work conditions that are particularly harmful for health, should be allowed to draw their state pension earlier, after having completed a minimum number of years in that occupation. We do not, however, assume that all such workers on receipt of their pension will 
retire from the workforce. Rather, in many cases, workers may well prefer to move to part-time work, perhaps phasing in full retirement over many years, rather than making an abrupt transition from full-time work to complete retirement. There are numerous ways in which the details of such policies could be worked out, and we will not consider the precise details of any such scheme here. Rather we want to make the argument that phased retirement can be expected to improve health for everyone, and starting that process earlier for those in the most physically demanding jobs may well be beneficial from the point of view of reducing inequalities in health.

Generally, we find the most harmful work conditions in occupations that require no or only low levels of qualifications. Therefore, these employees tend to have left school early and started their work life at an early age. Under the current pensions system, if an individual starts working at age 16, he or she will be required to work for 49 years before being entitled to the state pension. Not only will this worker endure work conditions that are bad for health, but will also spend a substantially longer period of life at work compared to someone who undertakes a lengthy education.

We believe that if workers in such occupations can collect their state pension earlier, it would have a beneficial effect on their health. This health benefit would be mainly due to the worker's withdrawal from the exposure to environments and factors that are harmful to health. We would expect to see health improvements both in the prevalence of fatal and non-fatal disease (such as, for example, musculoskeletal disorders); thus, the health improvements would constitute improvements in well-being as well as increased life expectancy. As the change in policy that we recommend will affect mainly workers in lower grade occupations, who have the worst health and the lowest life expectancy, this improvement in health will at the same time constitute a reduction in the social gradient in health.

It has been suggested that, contrary to our supposition, (early) retirement is in fact bad for health. So far, however, the research has failed to establish this, although it is widely believed, and seems plausible that, working is good for mental health. If this is true, it presents a conundrum. If working is bad for physical health but retirement bad for mental health, what should we recommend? However, there appears to be a solution. The harm that working does to physical health probably has a dose-response in the sense that the more you do, the worse it is for you. Conversely, the good that working does for your mental health probably does not have a dose-response. That is, while it may be good to have a job to enjoy a sense of connectedness to others, and of worth and contribution, it probably makes little if any difference whether one works full-time or part-time. Hence, we believe, there is a stage in the life of a worker where part-time work, against a background of financial security, will be optimal for continued physical and mental health.

Furthermore, this proposal would also be an improvement from the point of view of fairness. With the current system, there is an inequality in the length of working life required to earn the state pension between different occupations. If low grade workers were allowed to retire earlier, this inequality would be reduced.

As the retirement age is set to increase, we believe that our proposal is particularly relevant. The expected rise will hit the lower socio-economic classes harder and reinforce the inequalities described in this article.

\section{How Inequality in Length and Quality of Working Life Contributes to the Health Gradient}

Work conditions, including both material and psychosocial aspects, constitute a very clear and substantial contribution to the social inequalities in health. Manual or routine work is particularly harmful for health, and thus this category of employees suffers a significant health disadvantage: one-third of male employees in their 50s in this category of work report a long-standing limiting illness. By comparison, similar rates for men from professional and managerial backgrounds are not reached until they are aged over 75 : what Yeandle (2005: 2) refers to as a '20 year "illness gap"'.

Today, we know a lot about the various health risks that may be present in the work environment. A recent WHO report on work and health usefully suggests a classification of four different types of occupational health risks: physical, chemical, ergonomic and psychosocial (Benach et al., 2009). This would include hazards such as unshielded machinery, noise, vibrations, radiation; air pollution (such as smoke, fumes, dust or powder), chemicals; repetitive movements, hard physical labour; and low control.

The first three occupational hazards, physical, chemical and ergonomical, naturally constitute a much bigger problem in developing countries. Nevertheless, even 
within the EU-15, 121,000 people die each year from an occupational injury or work-related disease (ILO, 2005). It has been reported that the prevalence of many of these health risks within the EU has remained stable or has increased in the last 15 years (Parent-Thirion et al., 2007). These occupational hazards cause injuries, disease, stress, job dissatisfaction and reduced well-being (WHO, 1995).

The fourth occupational health hazard, psychosocial stress, is caused by a combination of factors. Two models have been proposed to explain how different aspects of the psychosocial work environment combine to cause stress. The demand-control model (Karasek and Theorell, 1991) is concerned with demand, which refers to stress caused by a heavy work load, and control, which reflects the worker's degree of decision latitude and opportunities to develop new skills. According to this model, a combination of high demand and low control, also referred to as 'job strain', constitutes a significant health risk; in particular, it increases the risk of heart disease. Research has largely confirmed this hypothesis (Bosma et al., 1998; Stansfeld et al., 1999; Ostry et al., 2003). Siegrist's (1996) effort-reward imbalance model is very similar-its central idea is that high effort (equivalent to demand) combined with low reward (in the form of e.g. money, recognition, possibilities for promotion or personal progress or job security) will expose the worker to high levels of stress, which in turn leads to an increased risk of mental and physical health problems. The empirical evidence confirms this relationship (Bosma et al., 1998; Ostry et al., 2003; Siegrist et al., 2004). Employment conditions can also cause stress. In particular, long or irregular hours, shift work, temporary work and job insecurity are known risk factors associated with worse mental and physical health, in particular common mental health problems and musculoskeletal disorders (Marmot Review, 2010).

The extent to which workers are exposed to such hazards varies widely, of course, depending both on national and local factors. Generally, however, the prevalence of these risk factors-physical, chemical, ergonomical and psychosocial-is unequally distributed across the occupational grade hierarchy: lower grade workers experience a higher exposure to such risk factors than higher grade workers. According to the WHO report (Benach et al., 2009), physical, chemical and ergonomic hazards are more prevalent in lower grade occupations. The lower the occupational grade, the more likely the worker is to be exposed to adverse work conditions such as physical strain, noise and air pollution and monotonous work (Schrijvers et al., 1998; Vahtera et al., 1999; Evans and Kantrowitz, 2002). Manual workers, in particular, are much more frequently exposed to physical and chemical risks; mining, manufacturing and construction are high-risk sectors (Benach et al., 2009). As for psychosocial risk factors, there is a less clear social gradient in the distribution of the risks. Generally, low job control is known to be more prevalent in lower grade occupations (Schrijvers et al., 1998; Vahtera et al., 1999; Siegrist, 2004; Marmot review, 2010). On the other hand, workers in higher grade occupations may be more at risk for exposure to higher job demands or greater work effort. However, if we look at the combination of factors (e.g. the balance between control and demand, and effort and reward), which is what determines the level of harmful stress, we find that lower grade occupations are generally worse (Tsutsumi et al., 2001; Kouvonen et al., 2006). Furthermore, lower grade workers may experience more stress from the same level of effort-reward imbalance (Siegrist 2004). Finally, workers from higher grade occupations may experience this form of job stress earlier on in their careers, whereas workers from lower grade occupations are more likely to be exposed to stress throughout their career (Chandola et al., 2005). Workers with lower qualifications will also more frequently suffer stress from low job stability and security and more frequently do shift work (Marmot Review, 2010). Overall, workers from the lower grade of the socio-economic spectrum are more likely to have bouts of unemployment and are at risk of being trapped in a cycle of worklessness and poor quality work with low pay, in part due to a decline in manufacturing and low-skilled jobs (Marmot Review, 2010). So for almost all forms of health hazards that may be associated with work, manual workers and workers with lower qualifications are more at risk. Because the occupations which work conditions are the most harmful to health are also generally the lower grade jobs for which no or only lower qualifications are required, workers in these occupations tend to have started working at an early age. Thus, they will also be exposed to adverse work conditions for longer. We can see, therefore, how work conditions make a significant contribution to the social gradient in health.

\section{Is the Current Pensions System Unfair?}

We do not wish to offer a comprehensive account of justice in retirement here. Generally, however, we think that the current practice of basing retirement on age would be considered unjust from any reasonable 
pro-egalitarian perspective. For the reasons outlined below, the current practice ends up being harsher, or more demanding, for those who are worse off, a result we expect all egalitarians would want to avoid.

First, workers in low-grade occupations spend more years in the workforce. Generally speaking, an inequality in time spent in the workforce may not in itself indicate any inequality in how well people are doing. After all, it is less clearcut that working is unequivocally a burden, and that being retired is unequivocally a benefit; working will have its own benefits, and retirement its downsides. People tend to consider leisure more attractive than working; common reasons cited for early retirement are being able to enjoy life while still young and fit enough, and to spend more time with a partner or family (DWP, 2003). But there may be benefits to working too, so retirement may not straightforwardly be preferable to working under all circumstances. However, the extent to which this is true clearly depends on what kind of job one has. Pertinent features of jobs are levels of job satisfaction, level of challenge, whether or not the job involves the ability to use skills and whether or not opportunities for development are available. Jobs with high levels of job satisfaction, the right level of challenge, that involve the ability to use skills and have opportunities for development will be much more rewarding than jobs with low job satisfaction, that are either too challenging (stressful) or not challenging enough (boring and monotonous), do not involve any use of skill and have no opportunities for development. Under the current pensions system, the workers who end up spending the most years at work before they can retire are also the employees with the worst work conditions and with the most to gain from retiring early. Second, because of the poor quality of their work conditions, these workers are more at risk for work-related health problems. The more time they spend at work, the more they are exposed to these work-related health risks. Therefore, having to work more years before they can retire will be bad for their health. Third, this group of employees has a shorter life expectancy. Life expectancy is currently increasing, but it is not increasing at the same rate for all socio-economic classes, and health inequalities seem to be increasing rather than decreasing. Thus, where retirement is determined by age, lower grade workers have a shorter retirement period to look forward to. This constitutes a disadvantage in two ways. First, in effect, each payment into the pension fund will generate less for the worker in terms of pension pay-outs, compared to someone with a longer life expectancy. Barnay (2007) estimated that in France, for an executive working for 39 years and retiring at 61 with a life expectancy at this time of 20.5 years, one worked year earns him 6.4 months of pension benefits, whereas for an unskilled worker, working for 40 years and retiring at 60 , with a continued life expectancy of only 15.5 years, each worked year earns him only 4.4 months of pension benefits. A greater difference in life expectancy and a bigger difference in length of careers will magnify the difference in months of pension benefits earned. Second, lower grade workers end up with less leisure and opportunity for rest and relaxation. The upshot is that not getting a higher education is associated with disadvantage on several levels in the current system where pension entitlement is based on age. Whereas inequalities in length of time spent in the workforce may not in themselves be just or unjust, we can see how, when the quality of working conditions is poor, working more rather than fewer years is a burden. Reducing this burden for the worst off would be an improvement from the point of view of justice, on any broadly egalitarian account.

Workers who start their career later in life usually do so because they spend more time in education. Of course, this is a consideration that is relevant to any comparison of the respective burdens and benefits of different types of work, and how to estimate the 'burden' of a longer working career versus a shorter working career. It is no easy task to develop a principled way in which to make such a comparison, and we recognize that the lack thereof is a shortcoming in an account of justice in work and retirement. On the other hand, an equally important question concerns the availability of places in higher education and the extent to which genuine equality of opportunity holds. This is particularly relevant in the UK at this time, as competition for university places is expected to become fiercer. The question of how we should compare the benefits and burdens of education versus work must be considered in light of this issue also.

\section{What can we do to Address these Inequalities? Our Proposal}

How can we address the inequalities we have identified in the previous sections? Below are some examples of retirement policies in other European countries (CESifo DICE 2007):

- In Cyprus, miners with at least 5 years of employment in a mine are entitled to old-age pension 1 month early for every period of 5 months of mining work, 
on the condition that they have retired from that occupation. (Although in no case can they draw pension before the age of 58.)

- In Estonia, workers in occupations that are considered particularly harmful to health (for example, employees in the metal, chemical or glass industry) are eligible for the Old-age Pensions Under Favourable Conditions up to 10 years before the legal retirement age, given that they have contributed to the workforce for at least 15-25 years, at least half of which must have been in the hazardous occupation.

- In Hungary, early retirement is available to those involved in jobs involving increased physical load or that are hazardous to health. Entitlement to pension starts 2 years earlier for those who have worked in such activities for at least 10 years (men) or 8 years (women), and pensionable age is further reduced by 1 year for every additional period of 5 years (men) or 4 years (women).

- In Poland, early retirement is available for persons working in unhealthy conditions or performing a specified type of work: workers can retire 5 years (journalists, rail workers), 10 years (miners, steel workers, divers) or 15 years (wind instrument musicians) before state pension age.

Austria, Italy, Portugal, Romania and Spain have comparable arrangements in place. Typically, heavy workers are allowed to withdraw from the workforce up to 10 years before other workers without penalty, given that certain conditions have been met, such as the worker having reached a minimum age and having been working for a certain number of years, a minimum number of which must be under hard labour conditions.

We note, of course, that not all countries regard the same occupations as meriting favourable retirement arrangements. We do not wish to settle the question here of how to classify all occupations, but rather to argue that if we were to adopt a policy of this kind in the UK, there is good reason to believe that health inequalities could be reduced as a result. We propose an arrangement whereby workers from occupations associated with high exposure to health risks should be allowed to draw the state pension earlier, based on a minimum number of years in the workforce rather than age. However, we are not suggesting that workers should be required to leave their job when they have completed the criteria for receiving the state pension (i.e. compulsory retirement); rather, we are suggesting that they can draw their pension whether or not they choose to continue working. We hope that workers will be encouraged to reduce their work hours, or change to a less demanding or less hazardous job. Thus, workers will be able to withdraw from a harmful work environment, reduce stress and benefit from more rest and relaxation. We believe that this is likely to improve the health of these workers. Because workers in the relevant occupations will predominantly be from lower socio-economic classes, a health improvement in this group will also constitute a reduction of the social gradient of health.

Furthermore, this arrangement would also be preferable from the point of view of justice. Many workers who start their working lives at an early age will now be able to retire earlier, such that their working lives will be more similar in length to that of workers with higher qualifications. They will also, of course, be able to enjoy a longer retirement period.

\section{Will our proposal really achieve the expected results?}

It could be questioned whether our proposal would really achieve the improvement in health that we have hypothesized. Doubts have been expressed as to whether retirement is indeed good for one's health-some argue that retirement will lead to a deterioration in health.

Unfortunately, there are relatively few studies on the topic of retirement and health, and the findings have been mixed: some studies show retirement to be beneficial for health (Gall et al., 1997; Drentea, 2002; Mein et al., 2003; Mojon-Azzi et al., 2007), some that retirement has no effect on health (Ekerdt et al., 1983; Butterworth et al., 2006; Villamil et al., 2006; van Solinge, 2007), and some that health deteriorates after retirement (Bossé et al., 1987; Morris et al., 1994; Buxton et al., 2005; Tsai et al., 2005; Bamia et al., 2007; Alavinia and Burdorf, 2008;).

Furthermore, there are some reasons why we ought to be cautious when interpreting the findings of some of this research. First, and most importantly, it is well established that the health of early retirees is generally worse than the health of the working population of comparative age (Alavinia and Burdorf, 2008). However, we also know that poor health is one of the major reasons for early retirement (McGoldrick, 1989; Monden, 2005; Cai and Kalb, 2006). This selection bias, the so-called healthy worker effect (Debrand and Lengagne, 2008), makes research on the causal relationship difficult, and we cannot merely compare the health of early retirees with the health of late retirees in order to investigate what effect retirement may have on health. Several of the studies that linked early retirement with 
deteriorating health failed to control for the reason for retirement (Buxton et al., 2005; Tsai et al., 2005; Bamia et al., 2007; Alavinia and Burdorf, 2008). Second, among early retirees we will also find workers who have been made redundant and 'forced' into early retirement, but who are classified as early retirees rather than unemployed. But it is possible that exiting the labour market in this way has different effects on health than retiring voluntarily. In fact, it has been established that being made redundant has a clear and immediate negative effect on health, aside from the long-term consequences of being unemployed (Stuckler et al., 2009). This is a further reason to account for workers' reasons to exit the labour market. Third, we also know that men of lower socio-economic class and with lower education tend to retire earlier than men from higher socio-economic classes (DWP, 2003; DTI, 2003; Buxton et al., 2005; Baima et al., 2007). Thus, the socio-economic make-up of early retirees may also play a part in explaining the worse health of this group. Finally, it seems likely that the type of work from which one retires will have an impact on how retirement affects health. If retirement is bad for the health, this may at least in part have to do with certain benefits associated with working and staying active, such that when one retires one loses these benefits, and as a consequence, one's health suffers. But the extent to which working is beneficial to health would likely depend on what kind of work one does and the nature of one's work conditions. As reviewed in the previous sections, many forms of work involve the exposure to several health risks. If work or staying active is in principle good for your health, we still need to consider the possibility that these beneficial effects may be outweighed by such health hazards. Even if working is beneficial for health in some way, the 'net' health effect of working as opposed to being retired cannot be taken for granted. It seems, therefore, that we ought to look at the effect of retirement separately for different occupations. In fact, Westerlund and his colleagues (2009) did precisely that and found that retirement had different effects on self-perceived health depending on what kind of work the employee had previously been doing. Interestingly, the more strenuous and demanding the employee's work conditions, the worse his or her health trajectory prior to retirement, and the greater the health improvement after retirement. The only group of employees who did not see any improvement in health after retirement, were workers of a high occupational grade, with low demands and high jobsatisfaction.
Clearly, more, and more sophisticated, research is needed before we can say with certainty how retirement affects health. However, it is worthwhile reviewing the reasons why we might think retirement is either good or bad for one's health.

Why would we think that retirement would be beneficial for health? As already mentioned, if in one's work environment one is exposed to various health hazards, or if one's work involves difficult work postures, work movements or handling of heavy loads, retiring from work will entail no longer being exposed to such harmful influences, which in all likelihood will be beneficial for one's health. Furthermore, rest, relaxation and reduced stress should also have health benefits. In addition, one may have more time to take exercise, as well as time to pursue hobbies and spend time with friends and relatives, which may improve well-being and quality of life.

On the other hand, in what ways might retirement be bad for the health? We know that unemployment is bad for the health, and one might therefore think that the same would be true of retirement, also being a form of non-participation in the workforce. Unemployment is thought to affect health mainly in three different ways. First, through loss of income and resulting financial problems, which in turn may lead to lower living standards, reduced social integration and reduced self-confidence (Maier et al., 2006). Second, through distress, anxiety and depression (Voss et al., 2004). Third, unemployment often leads to unhealthy behaviour such as smoking and drinking (Maier et al., 2006). Of these three causal pathways, the first one, loss of income and resulting poverty, is likely to be more relevant for retirement than the other two, but would be mitigated by entitlement to a state pension and the possibility of undertaking part-time work without loss of benefit. There are many significant differences between being made redundant and retiring, so if unemployment causes anxiety and depression, that in itself does not make it any more likely that retirement will have the same effect. Most people view retirement as more desirable than working, and this preference for retirement over work is even stronger for workers whose work is stressful, poorly paid and damaging for health (Lumsdaine and Mitchell, 1999; Blanchet and Debrand, 2005). It is possible that retirees will take up unhealthy habits, but on the other hand, having more time may give one more opportunity to choose a healthy lifestyle; cook homemade meals and take exercise, for example (Mein et al., 1998).

A few sociological theories make some suggestions as to why working may be beneficial, and accordingly, 
retirement harmful. For example, according to Structured Dependence Theory (Townsend, 1979), not being in work can make you feel dependent. According to Cumming and Henry's (1961) Disengagement Theory, being workless constitutes a form of withdrawal from society and will lead to social isolation or detachment and unhappiness. Or, Parson's (1942) Role Theory states that work is a central human activity, and that losing this role will lead to isolation and distress. Although there is some prima facie plausibility to these theories, it does not seem that retirement inevitably will have such an effect; the extent to which these relationships hold would vary depending on the individual's circumstances and values. Mein et al. (1998) conducted qualitative interviews with subjects from the Whitehall studies and found that retirees' experience did not conform to these theories. But in any case those who choose to continue in part-time work will not suffer these problems.

It has also been suggested that retirement itself can be a stressful event due to the major change to the individual's life that it constitutes (Barron et al., 1952; Rosow, 1974). On the other hand, according to Atchley's (1976) stage model of retirement, retirement may be experienced differently across time at different stages of retirement, as an adjustment process takes place. In contrast to views that retirement is a stressful event, Atchley suggested that the very start of the retirement period may be more like a honeymoon period, and that it is only later on in the retirement period that retirees experience disappointment and less satisfaction as their expectations of retirement may fail to be fulfilled. This phase may be followed by adjustment of expectations, acceptance and settlement into a daily routine. Gall et al. (1997) found support for such an adjustment process taking place, with a peak in psychological well-being 1 year after retirement, followed by some decline in well-being 6-7 years on. But overall retirement was seen as a positive experience. The pattern of adjustment to retirement may vary, however, individually, across gender, and across socio-economic class (Gall et al., 1997). And, once more, phased retirement, through part-time work, may have a smoothing effect.

Retirees' financial situation is likely to have a major impact on how they experience their retirement period. Not surprisingly, it has been reported that retirees with higher incomes are more satisfied than their peers with lower incomes (Gall et al., 1997). More generally, we know that poverty and low income is bad for health in a number of ways; both through the impact of material conditions such as housing, nutrition and clothing
(Black et al., 1982), as well as through the psychosocial stress associated with being poor (Marmot, 2004). Retiring into poverty will of course not be good for health. Westerlund et al. (2009), who reported an improvement in health after retirement, acknowledged that the workers in the sample were fortunate enough to have fairly generous retirement packages, and that this could have been important for the outcome; in other words, if retirement is potentially beneficial for health, this may be contingent on retirees having adequate means in retirement.

For all these reasons, then, we propose an arrangement whereby pension age and retirement age are separated. Thus, workers may choose to continue working in a reduced capacity while receiving the state pension. We believe that such an arrangement, combined with more opportunities for flexible working, will contribute to retirement overall having a beneficial effect on health. Being able to draw the state pension may enable workers to change to a less well paid but less demanding job where there is less exposure to health hazards. Or, a worker can stay in his job but afford to work reduced hours. In both cases, the worker will benefit from reduced stress and reduced exposure to health risks, as well as rest and relaxation. At the same time, however, by staying in work the worker will still benefit from features of work that are hypothesized to be good for one's health, such as keeping active, having a purpose, social support and income. If indeed retirement can have some negative effects on health, they are likely countered by being involved in work even on a part-time basis. The benefits of work are retained but the burden is reduced.

There is currently very little research on the potential impact of continued part-time work after retirement on health. One study, however, which found that retirement was associated with a decline in mental and physical health, reported that these negative health effects were reduced if the individual retired partially and continued to work part-time (Dave et al., 2008). A second longitudinal study supports this finding; Zhan et al. (2009) found that retirees who continued working after retirement (either in the form of part-time employment, self-employment or temporary employment) reported fewer major diseases and fewer functional limitations compared to individuals who had retired fully. Improved mental health was reported only by part-time workers who chose to continue working in their career field.

We concede, though, that existing studies are more suggestive than conclusive. Part of the difficulty, of course, is that this is not a field in which controlled 
experiments are possible, and natural experimentsstatistical studies - may well be confounded by many factors, such as possible selection bias. Nevertheless, arguments from justice are a reason for pursuing the policies we recommend here, independently of their effects on health. But we also believe that there is a strong case to be made that our proposal will contribute to improved health in the group of workers who currently have the lowest life expectancy and are exposed to the harshest work conditions.

\section{Funding}

This project was funded by the Crucible Centre at UCL. The Crucible Centre is part of the cross council Lifelong Health and Wellbeing Initiative. Funding from the BBSRC, EPSRC, ESRC and the MRC is gratefully acknowledged.

\section{Acknowledgements}

Our thanks to audiences in Cambridge, London and Paris for their comments on earlier versions of this article. This work was funded by a grant from the UCL Crucible Project.

\section{References}

Alavinia, S. M. and Burdorf, A. (2008). Unemployment and Retirement and Ill-health: A Cross-Sectional Analysis Across European Countries. International Archives of Occupational and Environmental Health, 82, 39-45.

Atchley, R. C. (1976). The Sociology of Retirement. New York: John Wiley and Sons.

Bamia, C., Trichopoulou, A. and Trichopoulos, D. (2007). Age at Retirement and Mortality in a General Population Sample. The Greek EPIC Study. American Journal of Epidemiology, 167, 561-569.

Barnay, T. (2007). Redistributive Impact of Differential Mortality in the French Pay-As-You-Go System. The Geneva Papers, 32, 570-582.

Barron, M. L., Streib, G. and Suchman, E. A. (1952). Research on the Social Disorganization of Retirement. American Sociological Review, 17, 479-482.

Benach, J., Muntaner, C., Solar, O., Santana, V., Quinlan, M. and the Emconet Network (2009).
Employment, Work, and Health Inequalities: A Global Perspective. Geneva: WHO.

Black, D., Morris, J. N., Smith, C. and Townsend, P. (1982). Inequalities in Health: The Black Report. London: Penguin.

Blanchet, D. and Debrand, T. (2005). Retirement Intentions, Health and Satisfaction at Work: an European Comparison, Issues in Health Economics IRDES No. 103.

Bosma, H., Peter, R., Siegrist, J. and Marmot, M. (1998). Two Alternative Job Stress Models and the Risk of Coronary Heart Disease. American Journal of Public Health, 88, 68-74.

Bossé, R., Aldwin, C. M., Levenson, M. R. and Ekerdt, D. J. (1987). Mental Health Differences among Retirees And Workers: Findings from the Normative Aging Study. Psychology and Aging, 2, 383-389.

Butterworth, P., Gill, S. C., Rodgers, B., Anstey, K. J., Villamil, E. and Melzer, D. (2006). Retirement and Mental Health: Analysis of the Australian National Survey of Mental Health and Well-being. Social Science \& Medicine, 62, 1179-1191.

Buxton, J. W., Singleton, N. and Melzer, D. (2005). The Mental Health of Early Retirees. National Interview Survey in Britain. Social Psychiatry and Psychiatric Epidemiology, 40, 99-105.

CESifo DICE. (2007). Conditions and Benefits for Early Retirement, available from: http://www.cesifo-group .de/portal/page/portal/ifoHome/a-winfo/d3iiv/ _DICE_division?_id=6745832\&_div $=6746069$ [Last accessed on 11 October 2010].

Chandola, T., Siegrist, J. and Marmot, M. (2005). Do Changes in Effort-reward Imbalance at Work Contribute to an Explanation of the Social Gradient in Angina? Occupational and Environmental Medicine, 62, 223-230.

Cai, L. and Kalb, G. (2006). Health Status and Labor Force Participation: Evidence from Australia. Health Economics, 15, 241-261.

Cumming, E. and Henry, W. E. (1961). Growing Old. New York: Basic Books.

Dave, D., Rashad, R. I. and Spasojevic, J. (2008). The Effects of Retirement on Physical and Mental Health Outcomes. Southern Economic Journal, 75, 497-523.

Debrand, T. and Lengagne, P. (2008). Working Conditions and Health of European Older Workers, Working Paper no. 8. Paris: Institut de recherche et documentation en économie de la santé.

Health Inequalities Unit, DH (Department of Health). (2008). Tackling Health Inequalities: 2007 Status 
Report on the Programme for Action. London: Department of Health.

Drentea, P. (2002). Retirement and Mental Health. Journal of Aging and Health, 14, 167-194.

DTI (Department of Trade and Industry). (2003). Retirement Ages in the UK: A Review of the Literature, Employment Relations Research Series, Research Report no. 18, available from: http://bis .ecgroup.net/Publications/EmploymentMatters/ EmploymentRelationsResearchSeries.aspx [Last accessed on 11 October 2010].

DWP (Department of Work and Pensions). (2003). Factors Affecting the Labour Market Participation of Older Workers, Norwich: Her Majesty's Stationery Office, available from: http://campaigns.dwp .gov.uk/asd/asd5/report_abstracts/rr_abstracts/ rra_200.asp [Last accessed on 11 October 2010].

Ekerdt, D. J., Baden, L., Bossé, R. and Dibbs, E. (1983). The Effect of Retirement on Physical Health. American Journal of Public Health, 73, 779-783.

Evans, G. W. and Kantrowitz, E. (2002). Socioeconomic Status and Health: The Potential Role of Environmental Risk Exposure. Annual Review of Public Health, 23, 303-331.

Gall, T. L., Evans, D. R. and Howard, J. (1997). The Retirement Adjustment Process: Changes in the Well-being of Male Retirees Across Time. Journal of Gerontology: Psychological Sciences, 52B, 110-117.

ILO (International Labour Organization). (2005). Introductory Report: Decent Work - Safe Work. Geneva: ILO.

Karasek, R. and Theorell, T. (1991). Healthy Work: Stress, Productivity, and the Reconstruction of Working Life. New York: Basic Books.

Kouvonen, A., Kivimäki, M., Virtanen, M., Heponiemi, T., Elovainio, M., Pentti, J., Linna, A. and Vahtera, J. (2006). Effort-reward Imbalance at Work and the Co-occurrence of Lifestyle Risk Factors: Cross-sectional Survey in a Sample of 36,127 Public Sector Employees. BMC Public Health, 6, 24.

Lumsdaine, R. L. and Mitchell, O. S. (1999). New Developments in the Economic Analysis of Retirement. In Ashenfelter, O. C. and Card, D. (eds), Handbook of Labor Economics. Amsterdam: North Holland, pp. 3261-3307.

Maier, R., Egger, A., Barth, A., Winker, R., Osterode, W., Kundi, M., Wolf, C. and Ruediger, H. (2006). Effects of Short- and Long-term Unemployment on Physical Work Capacity and on Serum Cortisol. International Archives of Occupational and Environmental Health, 79, 193-198.
Marmot, M., Allen, J., Goldblatt, P., Boyce, T., McNeish, D., Grady, M. and Geddes, I. (2010). Fair Society, Healthy Lives: The Marmot Review, Strategic Review of Health Inequalities in England post-2010.

Marmot, M. (2004). Status Syndrome. London: Bloomsbury Publishing.

McGoldrick, A. (1989). Stress, Early Retirement and Health. In Markides, K. and Cooper, C. (eds), Aging, Stress, and Health. Chichester: John Wiley and Sons.

Mein, G., Higgs, P., Ferrie, J. and Stansfeld, S. A. (1998). Paradigms of Retirement: the Importance of Health and Ageing in the Whitehall II Study. Social Science \& Medicine, 47, 535-545.

Mein, G., Martikainen, P., Hemingway, H., Stansfeld, S. and Marmot, M. (2003). Is Retirement Good or Bad for Mental and Physical Health Functioning? Whitehall II Longitudinal Study of Civil Servants. Journal of Epidemiology and Community Health, 57, 46-49.

Mojon-Azzi, S., Sousa-Poza, A. and Widmer, R. (2007). The Effect of Retirement on Health: a Panel Analysis using Data from the Swiss Household Panel. Swiss Medical Weekly, 137, 581-585.

Monden, C. W. (2005). Changing Social Variations in Self-assessed Health in Times of Transition. The Baltic States 1994-1999. European Journal of Public Health, 15, 498-503.

Morris, J. K., Cook, D. G. and Shaper, A. G. (1994). Loss of Employment and Mortality. British Medical Journal, 308, 1135-1139.

Ostry, A. S., Kelly, P., Dermers, P. A., Mustard, C. and Hertzman, C. (2003). A Comparison Between the Psychological Demand-reward Imbalance and Demand-control Models. BMC Public Health, 3, $10-27$.

Parent-Thirion, A., Macías, F. E., Hurley, J. and Vermeylen, G. (2007). Fourth European Working Conditions Survey. Dublin, Ireland: European Foundation for the Improvement of Living and Working Conditions.

Parsons, T. (1942). Age and Sex in the Social Structure of the United States. American Sociological Review, 7, 604-616.

Rosow, I. (1974). Socialization to Old Age. Berkeley: University of California Press.

Schrijvers, C. T., van de Mheen, H. D., Stronks, K. and Mackenbach, J. P. (1998). Socioeconomic Inequalities in Health in the Working Population: The Contribution of Working Conditions. International Journal of Epidemiology, 27, 1011-1018. 
Siegrist, J. (1996). Adverse Health Effects of Highpsychological Demand/Low-reward Conditions. Journal of Occupational Health Psychology, 1, 27-41.

Siegrist, J. (2004). An ESF Scientific Programme 19992003-Final Report, Duesseldorf: University of Duesseldorf, Medical Faculty. Social variations in health expectancy in Europe.

Siegrist, J., Starke, D., Chandola, T., Godin, I., Marmot, M., Niedhammer, I. and Peter, R. (2004). The Measurement of Effort-reward Imbalance at Work: European Comparisons. Socil Science \& Medicine, 58, 1483-1499.

Stansfeld, S. A., Fuhrer, R., Shipley, M. J. and Marmot, M. G. (1999). Work Characteristics Predict Psychiatric Disorder: Prospective Results from the Whitehall II Study. Occupational and Environmental Medicine, 56, 302-307.

Stuckler, D., Basu, S., Suhrcke, M., Coutts, A. and McKee, M. (2009). The Public Health Effect of Economic Crisis and Alternative Policy Responses in Europe: An Empirical Analysis. The Lancet, 374, 315-323.

Townsend, P. (1979). Poverty in the United Kingdom. Harmondsworth: Pelican.

Tsai, S. P., Wendt, J. K., Donnelly, R. P., de Jong, G. and Ahmed, F. S. (2005). Age at Retirement and Long Term Survival of an Industrial Population: Prospective Cohort Study. British Medical Journal, 331, 995.

Tsutsumi, A., Kayaba, K., Tsutsumi, K. and Igarashi, M. (2001). Association Between Job Strain and Prevalence of Hypertension: A Cross Sectional Analysis in a Japanese Working Population with a Wide Range of Occupations: The Jichi Medical School Cohort Study. Occupational and Environmental Medicine, 58, 367-373.
Vahtera, J., Virtanen, P., Kivimäki, M. and Penti, J. (1999). Workplace as an Origin of Health Inequalities. Journal of Epidemiology and Community Health, 53, 399-407.

van Solinge, H. (2007). Health Change in Retirement: A Longitudinal Study Among Older Workers in the Netherlands. Research on Aging, 29, 225-256.

Villamil, E., Huppert, F. A. and Melzer, D. (2006). Low Prevalence of Depression and Anxiety is Linked to Statutory Retirement Ages Rather Than Personal Work Exit: A National Survey. Psychological Medicine, 36, 999-1009.

Voss, M., Nylén, L., Floderus, B., Diderichsen, F. and Terry, P. D. (2004). Unemployment and Early Cause-specific Mortality: A Study Based on the Swedish Twin Registry. American Journal of Public Health, 94, 2155-2161.

Westerlund, H., Kivimäki, M., Singh-Manoux, A., Melchior, M., Ferrie, J. E., Pentti, J., Jokela, M., Leineweber, C., Goldberg, M., Zins, M. and Vahtera, J. (2009). Self-rated Health Before and After Retirement in France (GAZEL): a Cohort Study. The Lancet, doi:10.1016/S01406736(09)61570-1.

WHO. (1995). The World Health Report: Bridging the Gaps. Geneva: WHO.

Yeandle, S. (2005). Older Workers and Work-life Balance. In Hirsch, D. (ed.), Sustaining Working Lives: A Framework for Policy and Practice. York: Joseph Rowntree Foundation.

Zhan, Y., Wang, M., Liu, S. and Shultz, K. S. (2009). Bridge Employment and Retirees' Health: A Longitudinal Investigation. Journal of Occupational Health Psychology, 14, 374-389. 